\title{
Illiterate lamp men and other problems in geodesy
}

\section{William M. Kaula}

Geodesy, 4th Edn. By G. Bomford. Pp.855. ISBN 0-19-851946-X. (Oxford University Press: 1980.) $£ 49, \$ 139$.

IN 1952 I was reassigned from a combat engineer battalion in the Fulda Gap to the Ohio State University in order to study geodesy. Upon arriving in Columbus that June, I met Professor W. A. Heiskanen, who said: "I'm going to Finland tomorrow for the summer. Here, study this book"' "This book" was the first edition of Bomford's Geodesy, just published. So that summer I spent many hours between classes under the trees (now gone) on the east bank of the Olentangy, gleaning geodesy from Geodesy.

Geodesy is a compendium, rather than a textbook or a treatise. It is the principal geodetic reference book in English. The main parts of this new edition are: horizontal control (196 pp.), vertical control (57 pp.), physical geodesy (118 pp.), artificial satellites (139 pp.), and appendixes and bibliography (186 pp.).

Virtues of the book and its author include comprehensiveness within geodesy, a strong geometrical intuition, keen insights about instrumentation and observations, a sensitivity to measuring errors - and good writing. Bomford has much better command of language than most scientists and engineers. His discussions of such topics as the effects of atmospheric refraction on theodolite or spirit-level measurements are a pleasure to read, being syntheses of practical experience, an analytical attitude and fluency of expression. His Indian past is manifest in passages such as "When supplies and transport are easy and with lamp men who can find their own way about, the programme presents no special problems, but in uninhabited country, or with illiterate lamp men, it calls for very careful thought . .. "'. Bomford's careful selection of tangential topics, practical (e.g. star catalogues) or scientific (e.g. geophysical implications of gravity anomalies) is also evident.

However, he is less at ease with the abstract and the mathematical. His treatments of potential fields and orbital dynamics are somewhat perfunctory, and these topics are made unnecessarily obscure by quoting complicated formulae, rather than discussing underlying principles. A saving grace is the frequent referencing; anyone trying to use Geodesy as a text (as I did) must resort to looking up the references to understand whence came The first of a new series, Current Reviews in Biomedicine, has been published by Elsevier/North-Holland. The paperback Towards Understanding Receptors, edited by J.W. Lamble, is a well-organized collection of 33 reviews largely taken from Trends in Pharmacological Sciences, and costs $£ 7, \$ 25$. many of the prickly-looking equations. Oddly incongruous with the quoted formulae in the main text are most of the appendixes, which include rather elementary explanations of matrix algebra, theory of errors, vectors and so on. Some of this matter is outmoded: for example, eight pages on the solution of matrix equations make no mention of square-root techniques, while four pages on harmonic analysis reference only books written before 1930, and do not mention fast Fourier transform methods. Such archaisms may unduly deter those who have had modern engineering educations from using the book.

The revisions between the 1971 and 1980 editions are major. The type appears to have been completely reset and the size of the book has risen by 17 per cent. This increase is almost entirely explicable by the greater space accorded to artificial satellite methods, which has not only more than tripled but has also been rearranged with respect to the other material. However, going through the two editions in parallel reveals many other detailed changes, such as increases in the space devoted to crustal movements, time standards, MSL-geoid difference and gyro-theodolites which are balanced by decreases in that allocated to map projections, mechanical chronographs, astrolabes etc. In the earlier parts, particularly, this compressive zeal was paragraph by paragraph. A loss of flavour sometimes results. Thus, what was in the 1952 edition:

Such an apparatus was used in India in 1880 [150], p.35, and another was used with the prismatic astrolabe in 1927-9 [151], but neither was entirely satisfactory. Possibly the principle was sound, but the mechanism imperfect. Recently R. Woolley (of the Commonwealth Observatory, Canberra) has made an apparatus on similar lines, which is reported to be satisfactory in the observatory, although possibly not easily portable. Full reports have not yet been published.

has now shrunk to: "Such an apparatus has been constructed from time to time, but no great use of the method has been reported". Unfortunately, this drive to prune and mend apparently flagged by the time the appendixes were reached.

Bomford's experience and perception in geodetic survey is particularly applicable to current problems of using past geodetic measurements to infer crustal movements. The relevant cautionary remarks appear in both the sections on control and those on crustal movements: for example "The differences cannot lightly be ascribed to crustal movements", and "Levelling has sometimes been less good than it looks". Several likely systematic errors are discussed, but the bite of specific examples is lacking, perhaps because the Survey of India was always stricter in its practices than was the US Coast and Geodetic Survey.

I must report that I found no errors, other than a few misprints. The defects are much more ones of selection and exclusion. In addition to those mentioned above, an oddity is the omission of the determination of longitudinal variations in the gravity field from satellite orbit perturbations, which is both conceptually simpler and more fruitful of geodetic results than the resonant effects which are included.

Nonetheless, if you have a geodetic problem, look it up in Bomford. If he doesn't give you the answer, he'll tell you where else to look.

William M. Kaula is a Professor of Geophysics at the University of California, Los Angeles.

\section{Material attraction}

\section{P. J. Grundy}

Ferromagnetic Materials: A Handbook on the Properties of Magnetically Ordered Substances. Vols 1 and 2. Edited by E.P. Wohlfarth. Vol.1 pp.634, ISBN 0-444-85311-1. Vol.2 pp.600, ISBN 0-444-85312-X. (NorthHolland: 1980.) Each volume Df1.210, $\$ 102.50$.

MANY textbooks and technical handbooks lay claim to the title of the definitive text. However, in order to prove its superiority over all comers, a book, like all championship contenders, must have all the necessary qualities. If all the promised material - a further two volumes are planned - is provided and published within a reasonable time, this work should, indeed, prove to be a champion.

The handbook is designed to cover as wide a range of material properties as possible. Its restrictive title of Ferromagnetic Materials is quickly extended by the subtitle to take account of the other varieties of magnetic ordering, and the subjects covered by the first two volumes are varied indeed. The contributing authors have been well chosen, are "experts" in their specialist fields and most are household names in magnetism.

Understandably, there is no obvious overall plan to the layout of the chapters, except that the first is by the editor and reflects his deep interest and involvement with work on the trio of ferromagnetic transition metals. The second chapter of the first volume, by Mydosh and Nieuwenhuys on dilute transition metal alloys, deals authoritatively with the complex and fascinating range of effects arising from the concentration changes and differing magnetic interactions of the 